\title{
Review
}

\section{XIAP as a ubiquitin ligase in cellular signaling}

\author{
S Galbán ${ }^{1}$ and CS Duckett ${ }^{\star, 1,2}$
}

The ability of the vertebrate X-linked inhibitor of apoptosis (XIAP) protein to directly suppress apoptotic cell death pathways has been the subject of much research. Studies of this broadly expressed protein have largely focused on the unique interactions between XIAP and caspases - proteases that conduct and participate in the ordered disassembly of the cell during apoptosis. However, relatively less attention has been given to the RING domain of XIAP, which functions as an E3 ligase to catalyze the ubiquitination of substrate proteins. Here, we discuss the evidence implicating the RING domain of XIAP in the ubiquitinmediated regulation of three, somewhat arbitrarily divided, categories of substrate: XIAP itself, XIAP-interacting proteins involved in apoptosis, and other targets whose physiological roles likely extend beyond cell death. Collectively, these multiple activities of XIAP show that this enigmatic protein participates in a range of cellular activities beyond apoptotic suppression. Cell Death and Differentiation (2010) 17, 54-60; doi:10.1038/cdd.2009.81; published online 10 July 2009

Despite the immeasurable value to the biomedical research community of readily accessible, easily searchable DNA sequence databases, a major challenge created by this explosion in the identification of new genes is to understand the physiological functions of their products. The $X$-linked Inhibitor of apoptosis $(X I A P)$ is a good example of this. Originally identified by its homology to the lap genes contained within the genomes of baculoviruses, ${ }^{1-3}$ which themselves were discovered in genetic screens for suppressors of cell death ${ }^{4,5}$, XIAP has been shown to participate in a range of cellular activities that include, but are not limited to, apoptotic regulation. ${ }^{6}$ This has created a challenge in understanding how XIAP can be such a versatile, multifunctional protein, and how these apparently unrelated cellular roles might be reconciled.

Cellular IAP (C-IAP) proteins contain between one and three baculovirus IAP repeats (BIRs), 70-residue zinc-binding domains that are named from their original discovery in baculoviruses and that resemble a classical zinc finger configuration. $^{7-9}$ XIAP contains three BIRs (Figure 1), which, together with flanking residues, can bind directly to caspases$3,-7$ and -9 , thereby inhibiting their proteolytic activity. The structural features of these interactions, together with the mechanisms by which XIAP can inhibit the enzymatic activities of these caspases, have been studied in detail, ${ }^{11}$ yet despite the abundance of biochemical data supporting an extremely high affinity of XIAP for caspases, there are surprisingly few published reports describing endogenous XIAP/caspase interactions. ${ }^{12}$ Nevertheless, based on these structural studies XIAP is considered to be the only mammalian IAP protein that can function as a direct, competitive inhibitor of the enzymatic activity of caspases through binding to their catalytically active sites. ${ }^{11}$

Although the presence of a BIR is often considered as the defining feature of IAPs, many c-IAPs contain a second class of domain, which is also found in the baculovirus proteins, a $\mathrm{C}_{3} \mathrm{HC}_{4}$ RING finger motif ${ }^{13}$ (Figure 1) whose functions were unknown when first discovered, but which are now widely accepted as participating in the ubiquitin-proteasome pathway through their roles as E3 ubiquitin ligases ${ }^{14}$ (see article by Catherine Day and colleagues). The RINGs of the IAPs are much more closely related to each other than they are to the RINGs found in other proteins, and are also located at the extreme carboxyl termini of IAPs in a remarkably conserved manner. In earlier groundbreaking studies, the RINGs of the antiapoptotic baculovirus IAPs were found to be essential for cytoprotection, ${ }^{5,15}$ at least in the context of a virus infection, and the inability of IAPs from other baculoviruses to suppress apoptosis was traced, in part, to the RING. Subsequent work revealed, however, that high-level, ectopic expression of isolated BIRs from baculovirus IAPs can confer protection, ${ }^{16,17}$ together indicating that the RINGs of these proteins might augment, but are not solely responsible for, the antiapoptotic effects of the IAP. As discussed below, the E3

${ }^{1}$ Department of Pathology, The University of Michigan Medical School, Ann Arbor, MI, USA and ${ }^{2}$ Department of Internal Medicine, The University of Michigan Medical School, Ann Arbor, MI, USA

${ }^{*}$ Corresponding author: CS Duckett, Department of Pathology and Internal Medicine, University of Michigan, BSRB, Room 2057, 109 Zina Pitcher Place, Ann Arbor, MI 48109-2200, USA. Tel: + 734615 6414; Fax: + 734763 2162; E-mail: colind@umich.edu

Keywords: XIAP; c-IAPs; RING; E3 ubiquitin ligase; NF-kB

Abbreviations: XIAP, X-linked inhibitor of apoptosis; BIR, baculovirus IAP repeat; IAP, inhibitor of apoptosis protein; C-IAP, cellular IAP; IBM, IAP-binding motif; Smac/DIABLO, second mitochondria-derived activator of caspase/direct inhibitor of apoptosis-binding protein with low pl; DIAP1 \& 2, Drosophila IAP protein 1 \& 2; XAF1, XIAP-associated factor; NF- $\kappa$ B, nuclear factor $\kappa$-light-chain-enhancer of activated B cells; TNF, tumor necrosis factor; TRAFs, TNF receptor-associated factors; TNFR, TNF receptor; JNK, c-Jun N-terminal kinase; BMP, bone morphogenetic protein; TGF- $\beta$, transforming growth factor- $\beta$; TAK1, TGF- $\beta$-activated kinase 1 ; TAB1, TAK1-binding protein 1; COMMD1, copper metabolism (MURR1) domain containing 1; TRAMP, transgenic murine model of prostate cancer; XLP, X-linked lymphoproliferative disease; Omi/HtrA2, high temperature requirement protein A2; CLPX, a regulatory component of mitochondrial Clp protease; LRPPR, leucine-rich pentatricopeptide repeat motif-containing protein; $\mathrm{GdH}$, glutamate dehydrogenase; Nsp4, Nipsnap 4; ER, endoplasmatic reticulum

Received 20.3.09; revised 21.5.09; accepted 27.5.09; Edited by G Melino; published online 10.7.09 


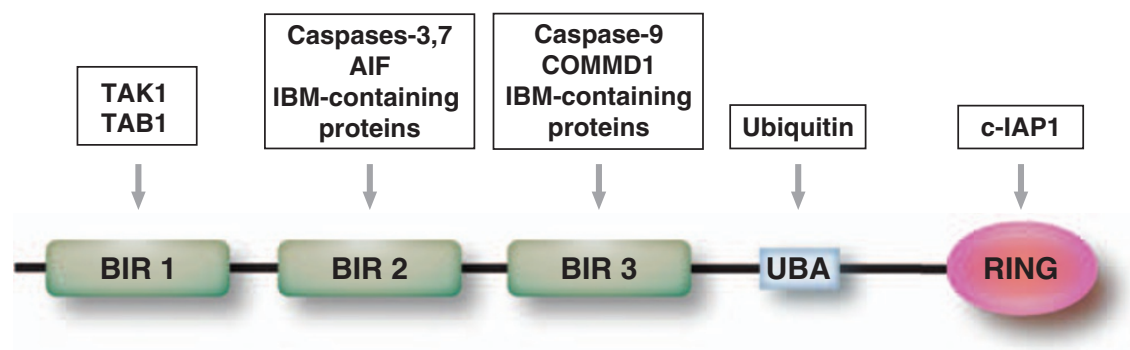

Figure 1 Structural representation of XIAP. XIAP contains three BIRs, a ubiquitin-binding domain (UBA) and a RING finger domain. TAB1 binds the BIR1 domain, whereas activated caspase-3 and -7 bind in an indistinguishable manner to a groove in BIR2 that also requires amino terminal flanking residues, which can competed by IAP-binding motif (IBM) containing proteins. The RING domain has been shown to be important for heterodimerization with c-IAP1 ${ }^{10}$

ligase activity inherent to the RING of XIAP plays a variety of roles that include, but are not limited to, apoptotic inhibition (Figure 3).

\section{Regulation of XIAP itself by Ubiquitination}

The realization that XIAP can be degraded through the ubiquitin-proteasome pathway emerged from a pivotal study by Yang et al. ${ }^{18}$ in which thymocytes that were induced to die by dexamethasone treatment could be rescued with proteasome inhibitors. From this earlier work, it became apparent that both XIAP, as well as another RING-containing IAP, C-IAP1, can be stabilized by proteasome inhibition, and that XIAP is capable of autoubiquitination in a manner dependent on its RING. The general assumption has been that the autoubiquitination of XIAP is a K48 ubiquitin conjugation process leading to proteasomal degradation (see accompanying article by Ciechanover and colleagues), although the types and degree of complexity of the ubiquitin chains formed have not been examined in detail. ${ }^{19}$ Nevertheless, the Yang study raised two major questions: first, does this occur because the cell is dying, or does the cell die as a consequence of the loss of XIAP? Second, at the molecular and structural level, how is XIAP ubiquitination regulated? The answers to these questions have remained elusive. Although it has been known for some time that Xiap-deficient mice seem healthy, are born at normal Mendelian ratios, and exhibit no obvious defects related to apoptosis, ${ }^{20,21}$ and dexamethasone-induced apoptosis of thymocytes from these and littermate control mice seem equally sensitive to apoptosis (J Wilkinson and CSD, unpublished data), more recent studies have revealed a more subtle modulatory role for XIAP in establishing the apoptotic threshold, which has been revealed by the analysis of murine and human XIAPdeficient cells using lower doses of apoptotic stimuli. ${ }^{22-24}$ Nevertheless, an obligate role for XIAP degradation in the induction of apoptosis can be excluded, and although cells from Xiap-deficient mice have been reported to express higher levels of other IAP proteins, ${ }^{20}$ the different physiological roles of these IAPs likely preclude redundancy or compensation as alternative interpretations.

The second question raised above, regarding the mechanisms by which XIAP is ubiquitinated, is still unresolved. In a recombinant, cell-free system, Yang et al. ${ }^{25}$ originally showed

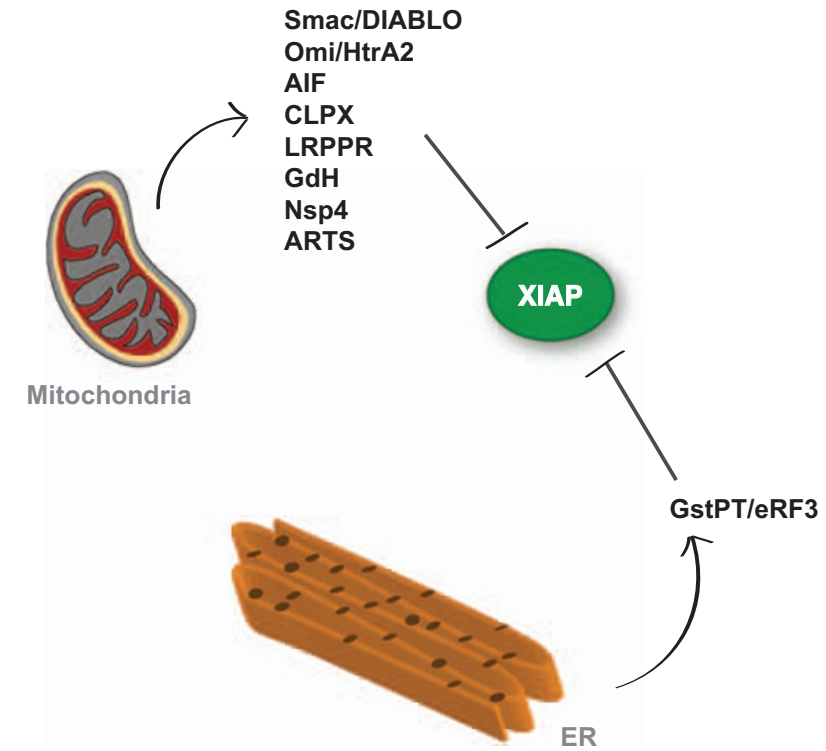

Figure 2 Mitochondrial and ER associated proteins antagonizing XIAP function. Mitochondrial proteins Smac/DIABLO, Omi/HtrA2, CLPX, LRPPR, GdH, Nsp4 or ER associated protein GstPT/eRF3 have all been described to bind and potentially antagonize XIAP through their IAP-binding motifs (IBMs). ${ }^{27}$ Apoptosis-inducing factor (AIF) and ARTS are thought to bind IAPs through distinct mechanisms independent of IBMs ${ }^{28,29}$

that XIAP can function as an E3 ubiquitin ligase to catalyze its autoubiquitination, but it has been a challenge to confirm this endogenously in living cells. An attractive model might be that the induced binding of XIAP-interacting proteins might confer a structural change in XIAP, which permits autoubiquitination. The best-characterized XIAP-interacting proteins, which were identified using affinity purification approaches, ${ }^{26,27}$ are diverse in sequence and structure but related by a tetrapeptide domain known as an IAP-binding motif (IBM), and are located in the mitochondria of non-apoptotic cells (Figure 2). In mammalian cells, the prototype of these IBM-containing proteins is second mitochondria-derived activator of caspase $(\mathrm{Smac})^{30}$ (also termed DIABLO (direct inhibitor of apoptosisbinding protein with low $\mathrm{pl})^{31}$ ), and is released from the mitochondria in response to apoptotic signals coincident 
with the release of cytochrome $c$ (Figure 2). Through steric occlusion of the domains used by XIAP to bind caspases, IBM-containing proteins such as Smac, as well as synthetic, small-molecule IBM mimetics, can neutralize the caspaseinhibitory properties of XIAP. Several studies have shown that in addition to reversing the caspase-inhibitory effects of $\mathrm{XIAP}$, IBM-bearing antagonists can, under some circumstances, trigger the degradation of XIAP in a RING-dependent manner. ${ }^{24,32-34}$ Although these studies are suggestive of autoubiquitination, not all reports reached the same conclusion, ${ }^{35,36}$ and others have revealed the ability of other RING-bearing IAPs, notably c-IAP1, to cause the ubiquitination of XIAP. ${ }^{37,38}$ As the RING of XIAP is also required for oligomerization, ${ }^{37}$ as well as for interaction with c-IAP1, it has been difficult to formally show that the ubiquitination of XIAP is caused by its own E3 activity, rather than that of another E3 ligase such as c-IAP1. For example, in a recent study using a murine model in which gene targeting was used to generate a truncated Xiap protein lacking the RING, higher basal levels of the truncated protein were observed, and this protein seemed more stable after apoptotic stimulation. ${ }^{39}$ Although it is possible that the RING is required for autoubiquitination, a formal alternative explanation is that the loss of the RING results in a version of XIAP unable to be ubiquitinated by c-IAP1. In either case, the ubiquitination of XIAP has been shown to occur primarily at lysine residues outside the RING domain itself, ${ }^{40}$ implying that the docking site of c-IAP1 and its target lysines on XIAP are separable domains. Additional studies, for example using mutants of the RING that lack the ability to autoubiquitinate but retain other functions, such as oligomerization $^{10}$ and perhaps C-IAP1 binding, will be helpful to further understand the mechanisms by which XIAP is ubiquitinated.

\section{Ubiquitination of XIAP-Interacting Proteins Involved in Apoptosis}

Given the remarkable degree of conservation of the IAP RINGs, yet the paucity of in vivo data regarding the ability of XIAP to autoubiquitinate as discussed above, several studies have addressed the question of whether XIAP can ubiquitinate caspases. Suzuki et al. ${ }^{41}$ described the ability of ectopically expressed XIAP to target the active form, but not the pro-form, of caspase-3 for ubiquitination and proteasomal degradation. However, Xiap-deficient mice were not found to express higher levels of caspase- 3 protein compared with control animals, ${ }^{20,39}$ although interestingly, higher levels of caspase-3 activity were observed in the RING-targeted mouse, despite no obvious differences in basal apoptotic sensitivity in the cell types examined. ${ }^{39}$ One implication of these data is that the ubiquitination of XIAP-associated caspases might not induce proteasomal degradation but could nevertheless inactivate the enzymatic activity of the caspase, as has been described for the Drosophila IAP protein (DIAP1). ${ }^{42}$

As discussed above, a number of reports have described the ability of IBM-containing proteins to cause the ubiquitination of XIAP on binding, even if the issue of whether this process is due to autoubiquitination or is induced by another E3 ligase may not have been definitively resolved (Figure 3). Evidence also exists to support the converse: ubiquitination of XIAP-associated proteins including $\mathrm{Smac}^{43}$ and apoptosisinducing factor ${ }^{28}$ has been shown to occur through a process that requires the RING of XIAP. XIAP has also been reported to induce the downregulation of another IAP family member, Survivin, by a mechanism requiring the associated factor, XAF1, and an intact XIAP RING. ${ }^{44}$ If these findings are

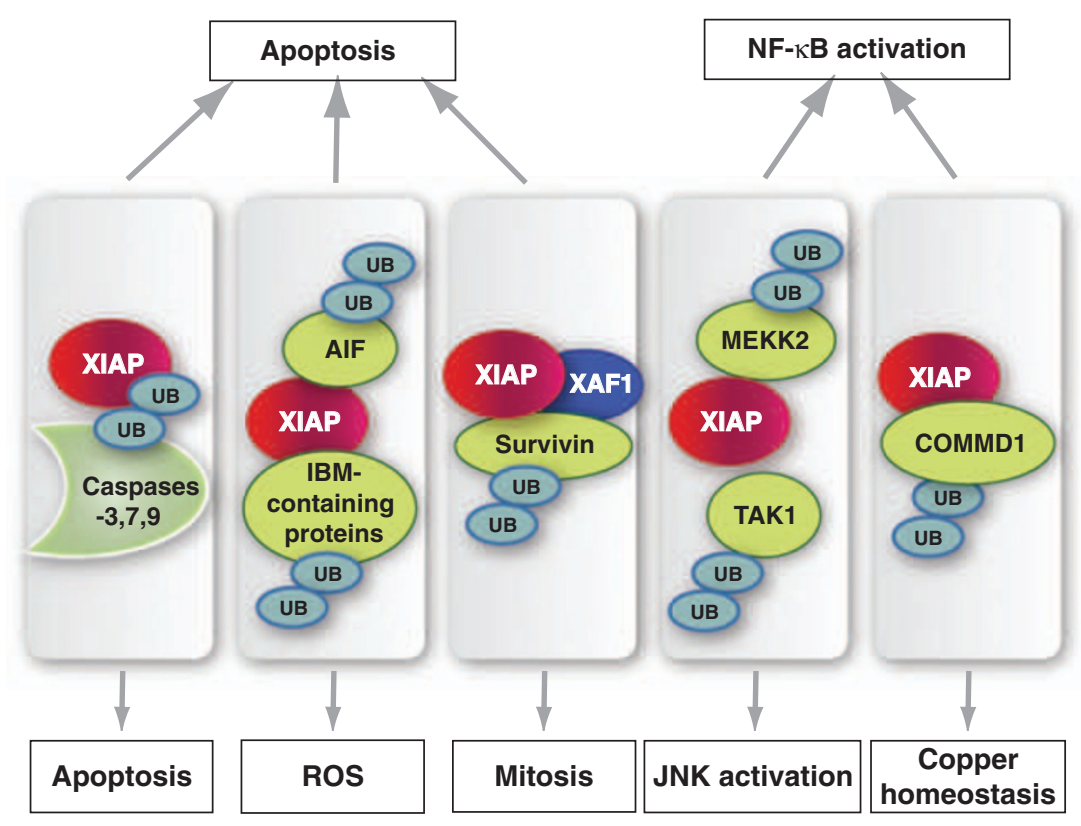

Figure 3 E3 ubiquitin-ligase substrates of XIAP. Binding proteins interact with XIAP through distinct domains, and ubiquitination has been shown for the depicted proteins. K48-linked ubiquitination and subsequent proteasomal degradation has been reported for copper metabolism (MURR1) domain containing 1 (COMMD1), apoptosis-inducing factor (AIF), TGF- $\beta$-activated kinase 1 (TAK1) and MEK kinase 2 (MEKK2) 
substantiated with endogenous levels of protein physiological conditions, it will be of great interest to identify the factors, other than mere cellular compartmentalization as is the case for mitochondrially located IAP-binding proteins, which regulate what seems to be a dynamic equilibrium between ubiquitinated XIAP and its associated proteins. Another provocative implication of this model is that proteins such as Smac, which are traditionally considered to participate solely in the apoptotic pathway, might participate in other cellular signaling cascades regulating, for example, nuclear factor $\kappa \mathrm{B}(\mathrm{NF}-\kappa \mathrm{B})$, and, by targeting these proteins for ubiquitination, XIAP might exert effects on the cell through processes not directly related to apoptotic cell death. ${ }^{17,45}$ If this turns out to be the case, clearly the distinction between targets of XIAP involved in apoptosis and non-apoptotic signaling becomes somewhat arbitrary, as discussed below.

\section{XIAP: A Signaling Intermediate Looking for a Pathway?}

The ordered hierarchy of events in which caspases are sequentially activated is itself a specialized signal transduction pathway, similar to the paradigm of the tissue factor pathway that regulates blood coagulation. ${ }^{46}$ In addition, it is becoming increasingly clear that caspases have diverse substrates, which are themselves key components of signaling pathways; ${ }^{47}$ for example, caspase- 3 has been shown to proteolytically cleave $\mathrm{I} \kappa \mathrm{B}$, the inhibitor of $\mathrm{NF}-\kappa \mathrm{B},{ }^{48}$ and presupposing that caspase- 3 can be enzymatically active under conditions in which the cell is not destined to die, XIAP might be expected to regulate NF- $\kappa \mathrm{B}$ activity through its caspase-3 inhibitory activity. In this light, XIAP in principle can be thought of as a signaling molecule simply through its ability to regulate caspases, without invoking any additional intracellular targets. However, experimental evidence is emerging to indicate that XIAP can also function as a signal transduction intermediate independent of its caspase-suppressing properties.

The means by which c-IAP1 and c-IAP2 were first isolated ${ }^{49}$ was highly anticipatory of the kinds of cellular roles played by IAPs. These proteins were originally identified as components of a cytoplasmic signaling complex containing members of the tumor necrosis factor (TNF) receptor-associated factors, TRAF1 and TRAF2 (see article by John Silke and colleagues), and these types of complexes have been shown to be recruited to the cytoplasmic domains of numerous members of the TNF receptor (TNFR) superfamily. TRAFs and c-IAPs are now known to participate in the activation of several conserved intracellular signaling pathways, notably the pleiotropic transcription factor NF- $\kappa \mathrm{B}$ and $\mathrm{C}$-Jun N-terminal kinase (JNK) cascades. ${ }^{6}$ Although XIAP is not thought to be a TRAF-binding protein, ${ }^{50,51}$ it has been implicated in the activation of NF- $\kappa \mathrm{B}^{52,53}$ and $\mathrm{JNK},{ }^{54}$ and therefore a candidate approach has largely been taken in an effort to identify an analogous cellular signaling pathway in which XIAP might participate. Evidence exists to suggest possible roles for XIAP in the innate immune response ${ }^{55}$ (e.g. through toll-like receptor and nucleotide-binding oligomerization domain containing protein signaling) as well as in the bone morphogenetic/transforming growth factor- $\beta$ (BMP/TGF- $\beta$ ) receptor- signaling pathways; ${ }^{52,56,57}$ however, there are less data to support roles for XIAP in these pathways compared with the well-established involvement of the c-IAPs in TNFR superfamily signaling. This is largely because endogenous c-IAP proteins have been readily identified as components of intracellular signaling complexes (particularly those activated by TNFR superfamily members), whereas to date XIAP has not.

The idea that certain IAPs might be involved in the TGF- $\beta$ / BMP signaling was first raised over a decade ago. The Drosophila IAP proteins, DIAP1 and DIAP2, were shown to associate with Thickveins, a Drosophila receptor for the BMPrelated ligand, Decapentaplegic. ${ }^{58}$ Subsequently, Yamaguchi et al. identified human XIAP, also through a yeast two-hybrid screen, by virtue of its interaction with the TGF- $\beta /$ BMP receptor-associated protein, TAB1 (Figure 1), and the same study revealed a functional role for XIAP as a component of a TGF- $\beta$-activated kinase 1/TAK1-binding protein 1 (TAB1/ TAK1) signaling complex in BMP-dependent Xenopus model of embryonic patterning. ${ }^{56}$ In ectopic expression studies, XIAP was later shown to coassociate with the TGF- $\beta$ type I receptor $(\mathrm{T} \beta \mathrm{RI})$ and to augment TGF- $\beta$-dependent gene expression. ${ }^{52} \mathrm{~A}$ specific element in the kinase domain of $\mathrm{T} \beta \mathrm{RI}$ known as the L45 loop was shown to be necessary for XIAP binding; ${ }^{57}$ as this loop is also required for Smaddependent signaling and JNK activation, these correlative data lend support to a model in which XIAP can modulate TGF- $\beta$-dependent signaling in a manner, which seems distinct from its caspase inhibitory role. Although deletion analyses in overexpression systems suggest that the E3 activity of XIAP is not required for TGF- $\beta$-mediated activation of either JNK or Smad-dependent signaling, ${ }^{59}$ differences in TGF- $\beta /$ BMPdependent signaling in XIAP-deficient cells and animals have not been described. Therefore, despite the existence of some evidence supporting a role for XIAP in TGF- $\beta$ /BMP signaling, in mechanistic and physiological terms this role remains to be fully characterized.

\section{XIAP and NF- $\kappa$ B: A Chicken-and-Egg Story}

Many studies have described the ability of $\mathrm{NF}-\kappa \mathrm{B}$ to transcriptionally activate the expression of XIAP. Paradoxically, however, a growing body of evidence also exists to support a modulatory role for XIAP in NF- $\kappa$ B activation. A number of earlier studies revealed the ability of ectopically expressed XIAP to activate NF- $\kappa$ B-responsive reporter activity. ${ }^{52,53,60}$ XIAP was shown to require an intact RING domain for this effect, ${ }^{52}$ suggesting a requirement for its ubiquitin ligase activity. However, the targets of XIAP in this process are less clear. An attractive candidate is the serine threonine kinase, TAK1, a MAPKKK originally identified as a signaling intermediate in the TGF- $\beta$ pathway that has been shown to form a complex with XIAP and TAB1. TAK1 is a major participant in NF- $\kappa$ B-inducing signals, ${ }^{61}$ and indeed studies have suggested that XIAP can trigger the ubiquitination of TAK $1^{62}$ through a mechanism that presumably requires an association with $\mathrm{TAB} 1,{ }^{56,63}$ and which is mediated by the most amino terminal BIR of XIAP (BIR1;64 Figure 1). An intriguing recent study also implicated a requirement for maximal NF- $\kappa \mathrm{B}$ activation of a conserved ubiquitin-binding 
domain, located between the BIR and RING domains. ${ }^{10}$ Conflicting data, however, have been described regarding the question of whether TAK1 is required for NF- $\kappa \mathrm{B}$-dependent activation by $\mathrm{XIAP},{ }^{52,53}$ and additional studies have suggested alternative pathways.

The originally described model of $\mathrm{NF}-\kappa \mathrm{B}$ regulation, in which a preformed p50:RelA heterodimeric complex is sequestered in the cytosol before activation of the appropriate signaling cascade, has stood the test of time. However, it has become clear that much of the NF- $\kappa \mathrm{B}$ response is regulated at the level of nuclear NF- $\mathrm{B}$, for example, by controlling the half-life of NF- $\kappa \mathrm{B}$ complexes on chromatin-associated promoters. ${ }^{65}$ One factor found to regulate the stability of NF- $\kappa \mathrm{B}$ subunits is copper metabolism (MURR1) domain containing 1 (COMMD1), a protein that seems to play a pivotal role in the targeted ubiquitination of chromatin-associated NF- $\kappa \mathrm{B}$ proteins, ${ }^{66}$ which was identified in an XIAP interaction screen (Figure 1$)^{67}$ and is itself a target of the ubiquitin ligase activity of XIAP. ${ }^{68}$ Therefore, an additional mechanism by which XIAP might modulate NF- $\kappa \mathrm{B}$-dependent transcription is to function as a negative regulator of the $\mathrm{NF}-\kappa \mathrm{B}$ suppressor, COMMD1 (Figure 3). The realization that COMMD1 itself is also involved in a variety of other cellular functions, including copper homeostasis $^{69}$ and hypoxia, ${ }^{70}$ leads to the interesting possibility that XIAP might also participate in these activities, and evidence exists to support this idea. ${ }^{6,71}$

While the activation of NF- $\kappa$ B by XIAP overexpression has frequently been observed as described above, until recently relatively few studies have examined the contribution to $\mathrm{NF}-\kappa \mathrm{B}$ signaling in vivo. XIAP-deficient cells do not show dramatic differences in NF- $\kappa \mathrm{B}$ signaling, compared with control cells ${ }^{20}$ and J Rumble and CSD, unpublished observations). NF- $\kappa \mathrm{B}$ activation is generally considered to support tumor development, but Xiap-targeted mice have been examined in the context of the TRAMP (transgenic murine model of prostate cancer) and found to trend toward more aggressive disease, ${ }^{72}$ which would not seem to support this model. In contrast, the RING-deficient Xiap-targeted mouse has been crossed to the $\mathrm{E} \mu$-Myc transgenic lymphoma model and found to skew toward enhanced survival, although it is important to note that the degree of NF- $\kappa$ B activation is clearly one of a large number of factors that determine tumor burden and disease progression. In addition, the expression of $\mathrm{NF}-\kappa \mathrm{B}-$ responsive genes in both of these models has not been described to date.

Two recent studies have implicated XIAP as a regulator of $\mathrm{NF}-\kappa \mathrm{B}$ in vivo. XIAP was found to play a pivotal role in the innate immune response to the cytosolic bacterial pathogen Listeria monocytogenes. Xiap-deficient mice were observed to be highly sensitive to this pathogen, and the activation of both NF- $\kappa \mathrm{B}$ and JNK was markedly impaired in macrophages, a primary target of $L$. monocytogenes, after infection. ${ }^{55}$ This suppression did not seem to lead to enhanced cellular apoptotic sensitivity, but rather seems to reflect an alteration in the secondary induction of proinflammatory cytokines, presumably as a consequence of impaired NF- $\kappa \mathrm{B} / \mathrm{JNK}$ dependent signaling. In addition, Winsauer et al. ${ }^{73}$ examined the kinetics of NF- $\kappa$ B activation by TNF in Xiap-deficient cells, and found a marked impairment, compared with that in control cells, of nuclear RelA(p65) in a second wave of activation that was found to occur around $60 \mathrm{~min}$ after stimulation. These interesting findings do not preclude a role for an XIAP/ COMMD1 regulatory mechanism, although the same study also showed the ability of overexpressed XIAP to coassociate with, and direct the ubiquitination of the NF- $\kappa \mathrm{B}$-activating kinase MEK kinase 2 (Figure 3), through a mechanism that seems to involve both K48- and K63-conjugated ubiquitin chains. This may become a more central issue for XIAP, as more is known about the physiological significance of distinct patterns of ubiquitination to proteasomal targeting, intracellular trafficking and functional regulation of the target protein. ${ }^{74}$

\section{XIAP, Ubiquitination and Cellular Signaling: The Road Ahead}

As discussed above, a growing body of evidence supports the notion that XIAP participates in cellular signaling cascades, and that the E3 ubiquitin ligase activity of this protein plays a key role in these processes. However, despite intensive studies, XIAP cannot yet definitively be placed in a physiologically confirmed 'wiring' diagram describing any specific receptor-initiated signaling cascade analogous to the positions of the c-IAPs in TNFR signaling. A quantum leap for the field would be to define such a role for XIAP, and currently the lead candidate pathways might seem to be those of the TGF$\beta / B M P$ receptors and the pattern recognition receptors of the innate immune system.

A potentially informative avenue into the physiological roles of XIAP may come from the recent identification of loss-offunction mutations in a subset of patients with $X$-linked lymphoproliferative disease (XLP), ${ }^{75}$ a primary immunodeficiency resulting in an inappropriate response to Epstein-Barr virus infection that frequently presents as a fatal hemophagocytic lymphohistiocytosis. ${ }^{76}$ Profiling of the hematopoietic repertoire and responsiveness of patients with mutations in XIAP to those with the primary cause of XLP, SLAMassociated protein, may help to shed light into the functional roles of XIAP, and as more mutations in XIAP are uncovered, ${ }^{77}$ this type of characterization may be highly illuminative.

Along with the search for specific cellular signaling pathways in which XIAP participates is the question of how its ubiquitin ligase properties are activated and regulated. It is most likely that the intrinsic biological activity of XIAP is controlled by cellular processes such as induced dimerization, transubiquitination, phosphorylation, proteolytic cleavage or subcellular compartmentalization; this is certain to be a highly fertile area of study in the future. Focus in the IAP field is currently moving towards the c-IAPs, due to the realization that synthetic IBM mimetics efficiently target the c-IAPs and represent an exciting new therapeutic approach to the treatment of disorders associated with cellular proliferation. ${ }^{78}$ It will be key to remember that the design of these mimetics was based, in almost every case, on the structural features of the XIAP/Smac interaction. ${ }^{6}$ Although it is a happy accident that these compounds exhibit an apparently higher efficacy for the C-IAPs than they do for XIAP, as attention is understandably turned to an examination of the physiological roles of the c-IAPs, XIAP clearly has yet to reveal many of its secrets. 
Acknowledgements. We thank our many colleagues and collaborators for their insightful comments and suggestions and we apologize to those scientists whose contributions, due to space limitations, we were unable to discuss. This work was supported by the NIH R01 GM067827 and an award from the American Asthma Foundation to CSD, and Immunopathology Training Grant T32HL07517) to SG.

1. Liston P, Roy N, Tamai K, Lefebvre C, Baird S, Cherton-Horvat G et al. Suppression of apoptosis in mammalian cells by NAIP and a related family of IAP genes. Nature 1996; 379: 349-353.

2. Duckett CS, Nava VE, Gedrich RW, Clem RJ, Van Dongen JL, Gilfillan MC et al. A conserved family of cellular genes related to the baculovirus iap gene and encoding apoptosis inhibitors. EMBO J 1996; 15: 2685-2694.

3. Uren A, Pakusch M, Hawkins C, Puls KL, Vaux DL. Cloning and expression of apoptosis inhibitory proteins homologs that function to inhibit apoptosis and/or bind tumor necrosis factor receptor-associated factors. Proc Natl Acad Sci USA 1996; 93: 4974-4978.

4. Birnbaum MJ, Clem RJ, Miller LK. An apoptosis-inhibiting gene from a nuclear polyhedrosis virus encoding a polypeptide with Cys/His sequence motifs. J Virol 1994; 68 : 2521-2528.

5. Crook NE, Clem RJ, Miller LK. An apoptosis-inhibiting baculovirus gene with a zinc fingerlike motif. J Virol 1993; 67: 2168-2174.

6. Srinivasula SM, Ashwell JD. IAPs: What's in a name? Mol Cell 2008; 30: 123-135.

7. Sun C, Cai M, Meadows RP, Xu N, Gunasekera AH, Herrmann J et al. NMR structure and mutagenesis of the third Bir domain of the inhibitor of apoptosis protein XIAP. J Biol Chem 2000; 275: 33777-33781.

8. Sun $\mathrm{C}$, Cai M, Gunasekera AH, Meadows RP, Wang $\mathrm{H}$, Chen $\mathrm{J}$ et al. NMR structure and mutagenesis of the inhibitor-of-apoptosis protein XIAP. Nature 1999; 401: 818-822.

9. Hinds MG, Norton RS, Vaux DL, Day CL. Solution structure of a baculoviral inhibitor of apoptosis (IAP) repeat. Nat Struct Biol 1999; 6: 648-651.

10. Gyrd-Hansen M, Darding M, Miasari M, Santoro MM, Zender L, Xue W et al. IAPs contain an evolutionarily conserved ubiquitin-binding domain that regulates NF- $\kappa \mathrm{B}$ as well as cell survival and oncogenesis. Nat Cell Biol 2008; 10: 1309-1317.

11. Eckelman BP, Salvesen GS, Scott FL. Human inhibitor of apoptosis proteins: why XIAP is the black sheep of the family. EMBO Rep 2006; 7: 988-994.

12. Deng $Y$, Lin $Y$, Wu X. TRAlL-induced apoptosis requires Bax-dependent mitochondria release of Smac/DIABLO. Genes Dev 2002; 16: 33-45.

13. Vaux DL, Silke J. IAPs, RINGs and ubiquitylation. Nat Rev Mol Cell Biol 2005; 6: 287-297.

14. Joazeiro CA, Weissman AM. RING finger proteins: mediators of ubiquitin ligase activity Cell 2000; 102: 549-552.

15. Clem RJ, Miller LK. Control of programmed cell death by the baculovirus genes $p 35$ and iap. Mol Cell Biol 1994; 14: 5212-5222.

16. Vucic D, Kaiser WJ, Miller LK. A mutational analysis of the baculovirus inhibitor of apoptosis Op-IAP. J Biol Chem 1998; 273: 33915-33921.

17. Wilkinson JC, Wilkinson AS, Scott FL, Csomos RA, Salvesen GS, Duckett CS Neutralization of Smac/Diablo by IAPs: a caspase-independent mechanism for apoptotic inhibition. J Biol Chem 2004; 279: 51082-51090.

18. Yang Y, Fang S, Jensen JP, Weissman AM, Ashwell JD. Ubiquitin protein ligase activity of IAPs and their degradation in proteasomes in response to apoptotic stimuli. Science 2000; 288: 874-877.

19. Lotocki G, Alonso OF, Frydel B, Dietrich WD, Keane RW. Monoubiquitination and cellula distribution of XIAP in neurons after traumatic brain injury. J Cereb Blood Flow Metab 2003; 23: 1129-1136.

20. Harlin H, Reffey SB, Duckett CS, Lindsten T, Thompson CB. Characterization of XIAP-deficient mice. Mol Cell Biol 2001; 21: 3604-3608.

21. Olayioye MA, Kaufmann H, Pakusch M, Vaux DL, Lindeman GJ, Visvader JE. XIAP-deficiency leads to delayed lobuloalveolar development in the mammary gland. Cell Death Differ 2005; 12: 87-90.

22. Cummins JM, Kohli M, Rago C, Kinzler KW, Vogelstein B, Bunz F. X-linked inhibitor of apoptosis protein (XIAP) is a nonredundant modulator of tumor necrosis factor-related apoptosis-inducing ligand (TRAIL)-mediated apoptosis in human cancer cells. Cancer Res 2004; 64: 3006-3008.

23. Rumble JM, Bertrand MJ, Csomos RA, Wright CW, Albert L, Mak TW et al. Apoptotic sensitivity of murine IAP-deficient cells. Biochem J 2008; 415: 21-25.

24. Galban S, Hwang C, Rumble JM, Oetjen KA, Wright CW, Boudreault A et al. Cytoprotective effects of IAPs revealed by a small molecule antagonist. Biochem J 2009; 417: 765-771.

25. Yang Y, Fang S, Jensen JP, Weissman AM, Ashwell JD. Ubiquitin protein ligase activity of IAPs and their degradation in proteasomes in response to apoptotic stimuli. Science 2000; 288: 874-877.

26. Vaux DL, Silke J. Mammalian mitochondrial IAP binding proteins. Biochem Biophys Res Commun 2003; 304: 499-504.

27. Verhagen AM, Kratina TK, Hawkins CJ, Silke J, Ekert PG, Vaux DL. Identification of mammalian mitochondrial proteins that interact with IAPs via N-terminal IAP binding motifs Cell Death Differ 2007; 14: 348-357.

28. Wilkinson JC, Wilkinson AS, Galban S, Csomos RA, Duckett CS. Apoptosis-inducing factor is a target for ubiquitination through interaction with XIAP. Mol Cell Biol 2008; 28: 237-247.
29. Gottfried $Y$, Rotem A, Lotan R, Steller $H$, Larisch $S$. The mitochondrial ARTS protein promotes apoptosis through targeting XIAP. EMBO J 2004; 23: 1627-1635.

30. Du C, Fang M, Li Y, Li L, Wang X. Smac, a mitochondrial protein that promotes cytochrome c-dependent caspase activation by eliminating IAP inhibition. Cell 2000; 102: 33-42.

31. Verhagen AM, Ekert PG, Pakusch M, Silke J, Connolly LM, Reid GE et al. Identification of DIABLO, a mammalian protein that promotes apoptosis by binding to and antagonizing IAP proteins. Cell 2000; 102: 43-53.

32. Fu J, Jin Y, Arend LJ. Smac3, a novel Smac/DIABLO splicing variant, attenuates the stability and apoptosis-inhibiting activity of X-linked inhibitor of apoptosis protein. J Biol Chem 2003; 278: 52660-52672.

33. Bertrand MJ, Milutinovic S, Dickson KM, Ho WC, Boudreault A, Durkin J et al. clAP1 and clAP2 facilitate cancer cell survival by functioning as E3 ligases that promote RIP1 ubiquitination. Mol Cell 2008; 30: 689-700.

34. Silke J, Kratina T, Ekert PG, Pakusch M, Vaux DL. Unlike Diablo/smac, Grim promotes global ubiquitination and specific degradation of $X$ chromosome-linked inhibitor of apoptosis (XIAP) and neither cause apoptosis. J Biol Chem 2004; 279: 4313-4321.

35. Yang QH, Du C. Smac/DIABLO selectively reduces the levels of c-IAP1 and c-IAP2 but not that of XIAP and livin in HeLa cells. J Biol Chem 2004; 279: 16963-16970.

36. Creagh EM, Murphy BM, Duriez PJ, Duckett CS, Martin SJ. Smac/Diablo antagonizes Ubiquitin ligase activity of inhibitor of apoptosis proteins. J Biol Chem 2004; 279 : 26906-26914.

37. Silke J, Kratina T, Chu D, Ekert PG, Day CL, Pakusch M et al. Determination of cell survival by RING-mediated regulation of inhibitor of apoptosis (IAP) protein abundance. Proc Natl Acad Sci USA 2005; 102: 16182-16187.

38. Cheung HH, Plenchette S, Kern CJ, Mahoney DJ, Korneluk RG. The RING domain of CIAP1 mediates the degradation of RING-bearing inhibitor of apoptosis proteins by distinct pathways. Mol Biol Cell 2008; 19: 2729-2740.

39. Schile AJ, Garcia-Fernandez M, Steller H. Regulation of apoptosis by XIAP ubiquitin-ligase activity. Genes Dev 2008; 22: 2256-2266.

40. Shin H, Okada K, Wilkinson JC, Solomon KM, Duckett CS, Reed JC et al. Identification of ubiquitination sites on the X-linked inhibitor of apoptosis protein. Biochem J 2003; 373: 965-971.

41. Suzuki Y, Nakabayashi Y, Takahashi R. Ubiquitin-protein ligase activity of X-linked inhibitor of apoptosis protein promotes proteasomal degradation of caspase-3 and enhances its anti-apoptotic effect in Fas-induced cell death. Proc Natl Acad Sci USA 2001; 98: 8662-8667.

42. Ditzel M, Broemer M, Tenev T, Bolduc C, Lee TV, Rigbolt KT et al. Inactivation of effector caspases through nondegradative polyubiquitylation. Mol Cell 2008; 32: 540-553.

43. MacFarlane M, Merrison W, Bratton SB, Cohen GM. Proteasome-mediated degradation of Smac during apoptosis: XIAP promotes Smac ubiquitination in vitro. J Biol Chem 2002; 277: 36611-36616.

44. Arora V, Cheung HH, Plenchette $\mathrm{S}$, Micali OC, Liston $\mathrm{P}$, Korneluk RG. Degradation of survivin by the X-linked inhibitor of apoptosis (XIAP)-XAF1 complex. J Biol Chem 2007; 282: 26202-26209.

45. Csomos RA, Wright CW, Galbán S, Oetjen KA, Duckett CS. Two distinct signalling cascades target the NF- $\kappa$ B regulatory factor C-IAP1 for degradation. Biochem J 2009; 420 : 83-91.

46. Furie B, Furie BC. Mechanisms of thrombus formation. N Engl J Med 2008; 359: 938-949.

47. Kim HS, Chang I, Kim JY, Choi KH, Lee MS. Caspase-mediated p65 cleavage promotes TRAIL-induced apoptosis. Cancer Res 2005; 65: 6111-6119.

48. Barkett M, Xue D, Horvitz HR, Gilmore TD. Phosphorylation of IkB-a inhibits its cleavage by caspase CPP32 in vitro. J Biol Chem 1997; 272: 29419-29422.

49. Rothe M, Pan M-G, Henzel WJ, Ayres TM, Goeddel DV. The TNFR2-TRAF signaling complex contains two novel proteins related to baculoviral inhibitor of apoptosis proteins. Cell 1995; 83: 1243-1252.

50. Roy N, Deveraux QL, Takahashi R, Salvesen GS, Reed JC. The C-IAP-1 and c-IAP-2 proteins are direct inhibitors of specific caspases. EMBO J 1997; 16: 6914-6925.

51. Duckett CS, Li F, Wang Y, Tomaselli KJ, Thompson CB, Armstrong RC. Human IAP-like protein regulates programmed cell death downstream of $\mathrm{Bcl}-\mathrm{xL}$ and cytochrome $\mathrm{c}$. Mol Cell Biol 1998; 18: 608-615

52. Birkey Reffey S, Wurthner JU, Parks WT, Roberts AB, Duckett CS. X-linked inhibitor of apoptosis protein functions as a cofactor in transforming growth factor-b signaling. $J$ Biol Chem 2001; 276: 26542-26549.

53. Hofer-Warbinek R, Schmid JA, Stehlik C, Binder BR, Lipp J, de Martin R. Activation of NF$\kappa \mathrm{B}$ by XIAP, the $\mathrm{X}$ chromosome-linked inhibitor of apoptosis, in endothelial cells involves TAK1. J Biol Chem 2000; 275: 22064-22068.

54. Sanna MG, Duckett CS, Richter BWM, Thompson CB, Ulevitch RJ. Selective activation of JNK1 is necessary for the anti-apoptotic activity of hILP. Proc Natl Acad Sci USA 1998; 95 $6015-6020$.

55. Bauler LD, Duckett CS, O'Riordan MX. XIAP regulates cytosol-specific innate immunity to Listeria infection. PLOS Pathog 2008; 4: e1000142.

56. Yamaguchi K, Nagai S, Ninomiya-Tsuji J, Nishita M, Tamai K, Irie K et al. XIAP, a cellular member of the inhibitor of apoptosis protein family, links the receptors to TAB1-TAK1 in the BMP signaling pathway. EMBO J 1999; 18: 179-187.

57. Itoh S, Thorikay M, Kowanetz M, Moustakas A, Itoh F, Heldin CH et al. Elucidation of Smad requirement in transforming growth factor- $\beta$ type I receptor-induced responses. J Bio Chem 2003; 278: 3751-3761. 
58. Oeda E, Oka Y, Miyazono K, Kawabata M. Interaction of Drosophila inhibitors of apoptosis with thick veins, a type I serine/threonine kinase receptor for decapentaplegic. J Biol Chem 1998; 273: 9353-9356.

59. Lewis J, Burstein E, Birkey Reffey S, Bratton SB, Roberts AB, Duckett CS. Uncoupling of the signaling and caspase-inhibitory properties of XIAP. J Biol Chem 2004; 279 9023-9029.

60. Levkau B, Garton KJ, Ferri N, Kloke K, Nofer JR, Baba HA et al. XIAP induces cell-cycle arrest and activates nuclear factor- $\kappa \mathrm{B}$ : new survival pathways disabled by caspasemediated cleavage during apoptosis of human endothelial cells. Circ Res 2001; 88: 282-290.

61. Shim JH, Xiao C, Paschal AE, Bailey ST, Rao P, Hayden MS et al. TAK1, but not TAB1 or TAB2, plays an essential role in multiple signaling pathways in vivo. Genes Dev 2005; 19: 2668-2681.

62. Kaur S, Wang F, Venkatraman M, Arsura M. X-linked inhibitor of apoptosis (XIAP) inhibits c-Jun N-terminal kinase 1 (JNK1) activation by transforming growth factor $\beta 1$ (TGF- $\beta 1$ ) through ubiquitin-mediated proteasomal degradation of the TGF- $\beta 1$-activated kinase 1 (TAK1). J Biol Chem 2005; 280: 38599-38608.

63. Sanna MG, Da Silva Correia J, Luo Y, Chuang B, Paulson LM, Nguyen B et al. ILPIP, a novel anti-apoptotic protein that enhances XIAP-mediated activation of JNK1 and protection against apoptosis. J Biol Chem 2002; 277: 30454-30462.

64. Lu M, Lin SC, Huang Y, Kang YJ, Rich R, Lo YC et al. XIAP induces NF- $\kappa$ B activation via the BIR1/TAB1 interaction and BIR1 dimerization. Mol Cell 2007; 26: 689-702.

65. Perkins ND. Integrating cell-signalling pathways with NF- $\kappa$ B and IKK function. Nat Rev Mol Cell Biol 2007; 8: 49-62.

66. Burstein E, Hoberg JE, Wilkinson AS, Rumble JM, Csomos RA, Komarck CM et al. COMMD proteins, a novel family of structural and functional homologs of MURR1. J Biol Chem 2005; 280: 22222-22232.

67. Ganesh L, Burstein E, Guha-Niyogi A, Louder MK, Mascola JR, Klomp LW et al. The gene product Murr1 restricts HIV-1 replication in resting CD4+ lymphocytes. Nature 2003; 426: 853-857.
68. Burstein $\mathrm{E}$, Ganesh L, Dick RD, van De Sluis B, Wilkinson JC, Lewis J et al. A novel role for XIAP in copper homeostasis through regulation of MURR1. EMBO J 2004; 23: 244-254.

69. van De Sluis B, Rothuizen J, Pearson PL, van Oost BA, Wijmenga C. Identification of a new copper metabolism gene by positional cloning in a purebred dog population. Hum Mol Genet 2002; 11: 165-173.

70. van de Sluis B, Muller P, Duran K, Chen A, Groot AJ, Klomp LW et al. Increased activity of hypoxia-inducible factor 1 is associated with early embryonic lethality in Commd1 null mice. Mol Cell Biol 2007; 27: 4142-4156.

71. Mufti AR, Burstein E, Csomos RA, Graf PC, Wilkinson JC, Dick RD et al. XIAP Is a copper binding protein deregulated in Wilson's disease and other copper toxicosis disorders. Mol Cell 2006; 21: 775-785.

72. Hwang C, Oetjen KA, Kosoff D, Wojno KJ, Albertelli MA, Dunn RL et al. X-linked inhibitor of apoptosis deficiency in the TRAMP mouse prostate cancer model. Cell Death Differ 2008; 15: 831-840.

73. Winsauer G, Resch U, Hofer-Warbinek R, Schichl YM, de Martin R. XIAP regulates bi-phasic NF- $\kappa$ B induction involving physical interaction and ubiquitination of MEKK2. Cell Signal 2008; 20: 2107-2112.

74. O'Riordan MXD, Bauler LD, Scott FL, Duckett CS. Inhibitor of apoptosis proteins in eukaryotic evolution and development: a model of thematic conservation. Dev Cell 2008; 15: 497-508.

75. Nichols KE, Ma CS, Cannons JL, Schwartzberg PL, Tangye SG. Molecular and cellular pathogenesis of X-linked lymphoproliferative disease. Immunol Rev 2005; 203: 180-199.

76. Rigaud S, Fondaneche MC, Lambert N, Pasquier B, Mateo V, Soulas $P$ et al. XIAP deficiency in humans causes an X-linked lymphoproliferative syndrome. Nature 2006; 444: 110-114.

77. Marsh RA, Villanueva J, Zhang K, Snow AL, Su HC, Madden L et al. A rapid flow cytometric screening test for $X$-linked lymphoproliferative disease due to XIAP deficiency. Cytometry $B$ Clin Cytom 2009 (in press)

78. Wu H, Tschopp J, Lin SC. Smac mimetics and TNF $\alpha$ : a dangerous liaison? Cell 2007; 131 $655-658$. 